\title{
Urinary Incontinence in Men in Uyo Metropolis, South-South, Nigeria
}

\author{
Udokang N. E. ${ }^{1}$, Inyang O. I. ${ }^{2,}$,, Dick U. P. ${ }^{1}$ \\ ${ }^{1}$ Department of Physiology, College of Health Sciences, University of Uyo, Uyo, Akwa Ibom State, Nigeria \\ ${ }^{2}$ Department of Physiology, College of Medicine, University of Ibadan, Ibadan, Oyo State, Nigeria
}

Email address:

otobonginyang2@yahoo.co.uk (Inyang O. I.)

${ }^{*}$ Corresponding author

\section{To cite this article:}

Udokang N. E., Inyang O. I., Dick U. P. Urinary Incontinence in Men in Uyo Metropolis, South-South, Nigeria. American Journal of Health Research. Vol. 4, No. 3, 2016, pp. 51-55. doi: 10.11648/j.ajhr.20160403.13

Received: March 4, 2016; Accepted: April 28, 2016; Published: May 14, 2016

\begin{abstract}
This study examined urinary incontinence and its possible risk factors in men living in Uyo Local Government Area, Akwa Ibom State, Nigeria. The study adopted a cross-sectional survey design and a questionnaire was developed and used as the major source of data collection. Sample of 320 men were randomly selected by simple random sampling and data were analyzed using frequency and percentage distribution, chi-square test, univariate and multiple logistic regression. Results of chi-square revealed a significant association $(p<0.05)$ between marital status and incontinence. The findings of this study have proven that urinary incontinence occurs as age increases.
\end{abstract}

Keywords: Incontinence, Risk-Factors, Infection, Prevalence, Respondents

\section{Introduction}

Urinary incontinence is the complaint of involuntary loss of urine. The prevalence of incontinence in men of all ages is certainly lower than that for women [1]. Urinary incontinence is common and it can have an impact on the physical, psychological and social well-being of sufferers, as well as their families and carers [2]. Greater incontinence symptom severity is associated with higher annual direct costs [3]. It is not strange that incontinence in men occur among young and older persons. While a specific etiologic cause of urinary incontinence is often identifiable in young persons, a multifactorial syndrome is more likely in older persons. There are several different etiologies that underlie the symptom of incontinence. In simple terms, incontinence may be a result of bladder dysfunction, sphincter dysfunction, or a combination of both [1]. Large studies have indicated that there is a $3 \%$ to $11 \%$ overall prevalence rate of incontinence in the male population, with urge incontinence being the prominent symptom reported in $40 \%$ to $80 \%$ of patients [4].

[5] Reported that incontinence is associated with advanced age, infections in the urinary tract, prostrate problems, nerve problems, bladder dysfunction, urethral dysfunction, bladder spasm, Alzheimer's disease and dementia. Researchers posit that any disease, condition, or injury that damages nerves can lead to urination problems [6]. Thus, nerve problems can occur at any age. In scientific parlance, diabetoneuropathy, Stroke, Parkinson's disease and multiple sclerosis are among the leading causes of incontinence in men. Also, overactive bladder is associated with urinary frequency, urinary urgency and urge incontinence.

As asserted by [7], urinary incontinence is governed by the sympathetic nerve supply, parasympathetic nerve supply and the somatic nerve supply, and failure of the above mentioned factors to be regulated appropriately predisposes individuals to urinary incontinence.

According to International Continence Society (ICS), urinary incontinence in men is classified into these basic categories; urge incontinence, overflow incontinence, stress incontinence, functional incontinence, continuous urinary incontinence, mixed incontinence and post micturition symptoms [8]. Overactive bladder results in leaking of urine [7] as seen in urge incontinence. As mentioned by [8], 
weakened pelvic floor muscles and tissues as a cause of stress incontinence. Functional incontinence occurs due to physical problems such as arthritis or cognitive problems such as dementia [9]. Delirium, infections, pharmacological substances and depression are associated with incontinence of varying degrees.

These varying degrees of incontinence affect males reproductively, diminish self confidence and ruin their social status. Most men deny themselves of the available medical attention, resorting to other measures that could offer them little or no help at all. More so, the poor attention given to this anomaly by the medical practitioners in this part of the globe makes this study imperative.

\subsection{Purpose of the Study}

This study seeks:

i. To determine the prevalence of urinary incontinence in men in Uyo metropolis, Akwa Ibom State, Southern Nigeria, based on the new International Continence Society (ICS) definitions.

ii. To find the etiologic causes of incontinence in men and encourage people with urinary incontinence to seek medical attention.

\subsection{Significance of the Study}

This study will create awareness on the prevalence of UI among men in Uyo metropolis and as well bring back the confidence of patients on how best UI could be managed if they seek medical attention.

\section{Methodology}

\subsection{Research Design}

Survey research design was adopted for this study. According to Creswell [10], this research design studies the nature and situation of things towards determining its situation as it exists at the time of investigation.

\subsection{Study Population/Area}

A population of three hundred and twenty (320) participants between the ages of 16-75years were used for the study. All the participants were residents of Uyo metropolis of Akwa Ibom State, Southern Nigeria, where the study was conducted.

\subsection{Instruments}

The instrument used for data collection was the Questionnaire designed by the researchers. The questionnaire was divided into four (4) sections;

Section A was designed to collect the respondents' personal data which include age, marital status, religion, and educational qualification.

Section B was designed to classify incontinence in men based on types.

Section $\mathrm{C}$ was designed to classify incontinence in men based on etiology.

Section D was designed to ascertain the respondents' approach to medical care.

\subsection{Research Procedure}

The instrument (questionnaire) was administered to the subjects personally by the researchers and their response rate was high. All the 320 questionnaires administered to the respondents were returned and found useable for the study.

\subsection{Statistical Analysis}

Chi-square test was used to determine the association in demographic variables of respondents and incontinence. One way analysis of variance (ANOVA) was used to analyse data, Frequencies and simple percentages were used to analyse qualitative variables. However, all hypotheses are tested at $\mathrm{P}<0.05$ level of significance.

\section{Results}

\subsection{Prevalence of Urinary Incontinence}

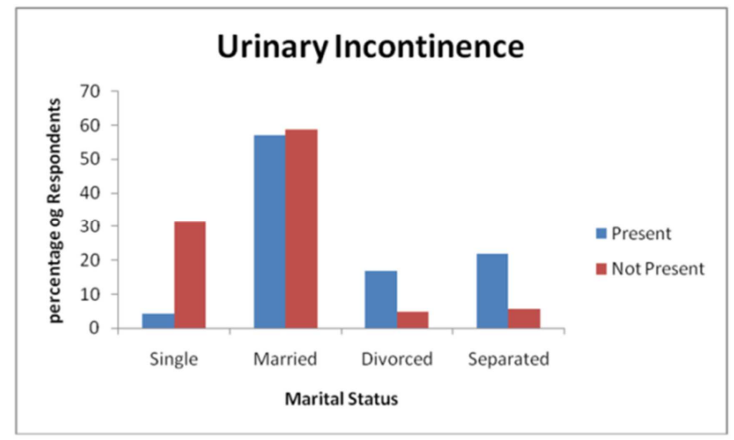

Figure 1. Bar Chart Showing the Distribution of Respondents by Marital Status.

Table 1. Distribution of Respondents by Age.

\begin{tabular}{llll}
\hline Age (years) & No. of Respondents with incontinence (\%) & No. of Respondents without incontinence (\%) & Total (n=320) \\
\hline $16-20$ & $4(3.4)$ & $32(15.9)$ & $36(11.2)$ \\
$21-25$ & $3(2.5)$ & $34(16.9)$ & $37(11.6)$ \\
$26-30$ & $4(3.4)$ & $34(16.9)$ & $38(11.9)$ \\
$31-35$ & $8(6.7)$ & $26(12.9)$ & $34(10.6)$ \\
$36-40$ & $14(11.8)$ & $19(9.5)$ & $33(10.3)$ \\
$41-45$ & $10(8.4)$ & $18(9.0)$ & $28(8.8)$ \\
$46-50$ & $28(23.5)$ & $24(11.9)$ & $52(16.2)$ \\
51 and above & $48(40.3)$ & $14(7.0)$ & $62(19.4)$ \\
\hline
\end{tabular}

$\mathrm{df}=7$, significant at $5 \%(\mathrm{p}<0.005)$; here, $\mathrm{P}<0.001$ 


\subsection{Etiologic Causes of Incontinence in Men}

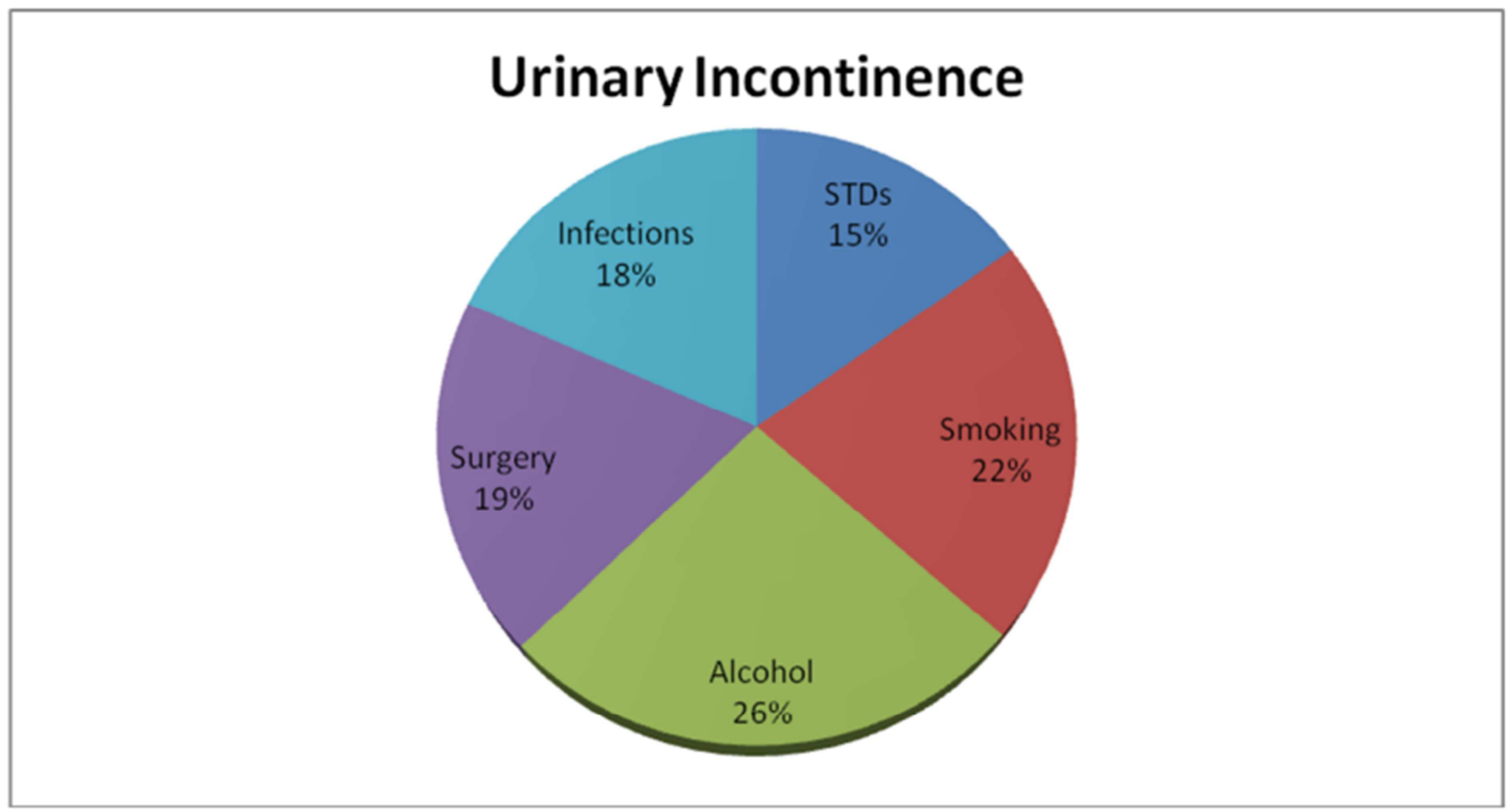

Figure 2. A pie chart showing etiologic causes of urinary incontinence in respondents.

\subsection{Types of Incontinence Found Among Respondents}

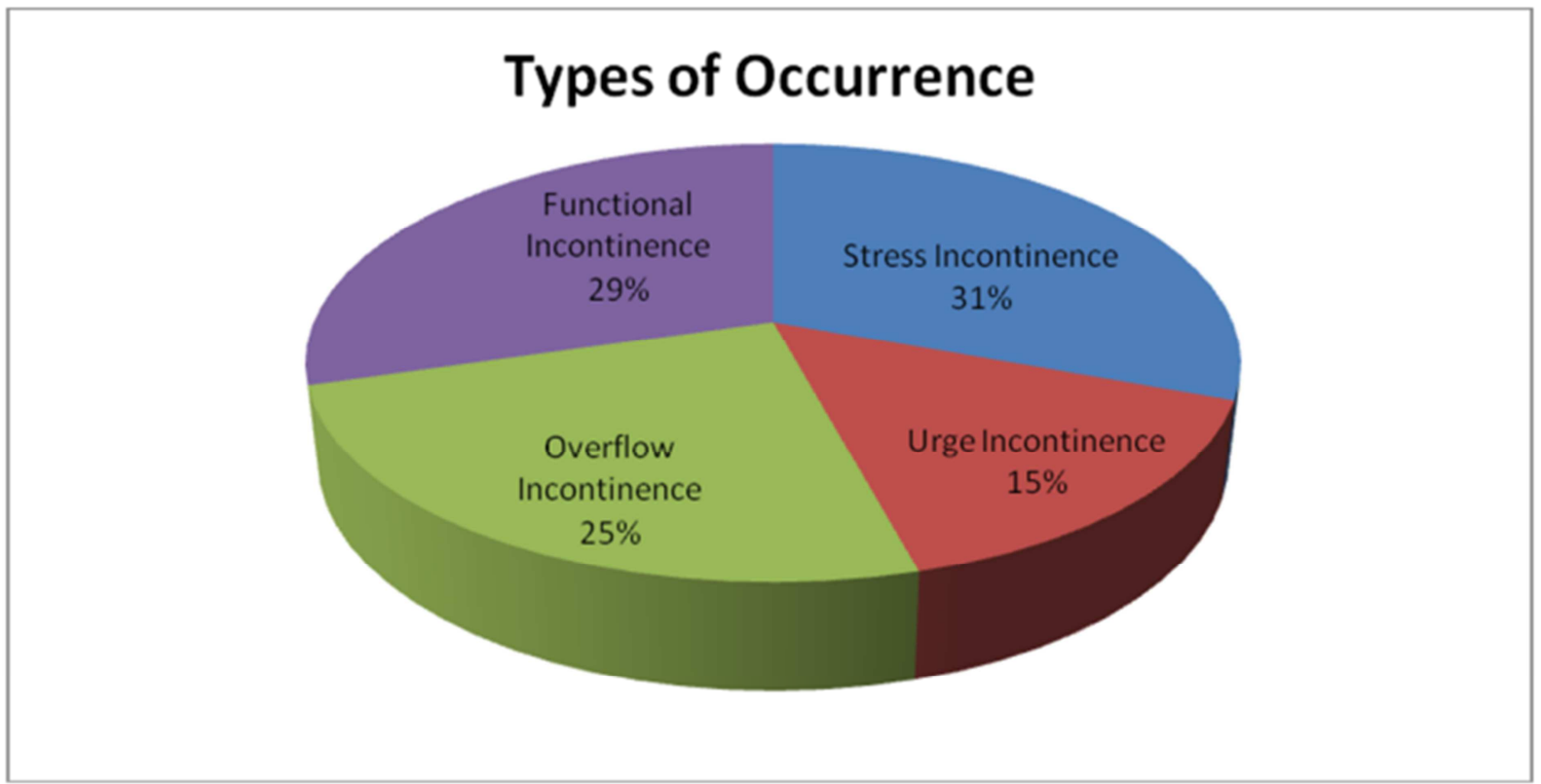

Figure 3. A pie chart showing the major types of urinary incontinence in respondents.

\subsection{Incontinence and Associated Risk Factors}

Table 2. Multiple Logistic Regression Showing Association between Incontinence and its Possible Risk Factors.

\begin{tabular}{|c|c|c|c|c|c|c|}
\hline Risk Factors & $\mathbf{B}$ & SE & Wald & OR & 95\% Confidence Interval & p-value \\
\hline Sexually Transmitted Disease (Yes/No) & 1.149 & 0.507 & 5.132 & 3.157 & $1.168-8.533$ & $0.023 *$ \\
\hline Smoking habit (Yes/No) & 1.359 & 0.493 & 7.612 & 3.890 & $1.482-10.218$ & $0.006^{*}$ \\
\hline Alcohol (Yes/No) & 0.441 & 0.467 & 0.892 & 1.55 & $0.623-3.878$ & 0.461 \\
\hline Previous Surgery Record (Yes/No) & 1.274 & 0.523 & 5.942 & 3.56 & $1.284-9.960$ & $0.015^{*}$ \\
\hline Presence of Blood in Urine/Infections (Yes/No) & 3.327 & 0.676 & 24.231 & 27.85 & $7.405-104.725$ & $<0.001^{*}$ \\
\hline
\end{tabular}

*Significantly different at $\mathrm{p}<0.05$ 


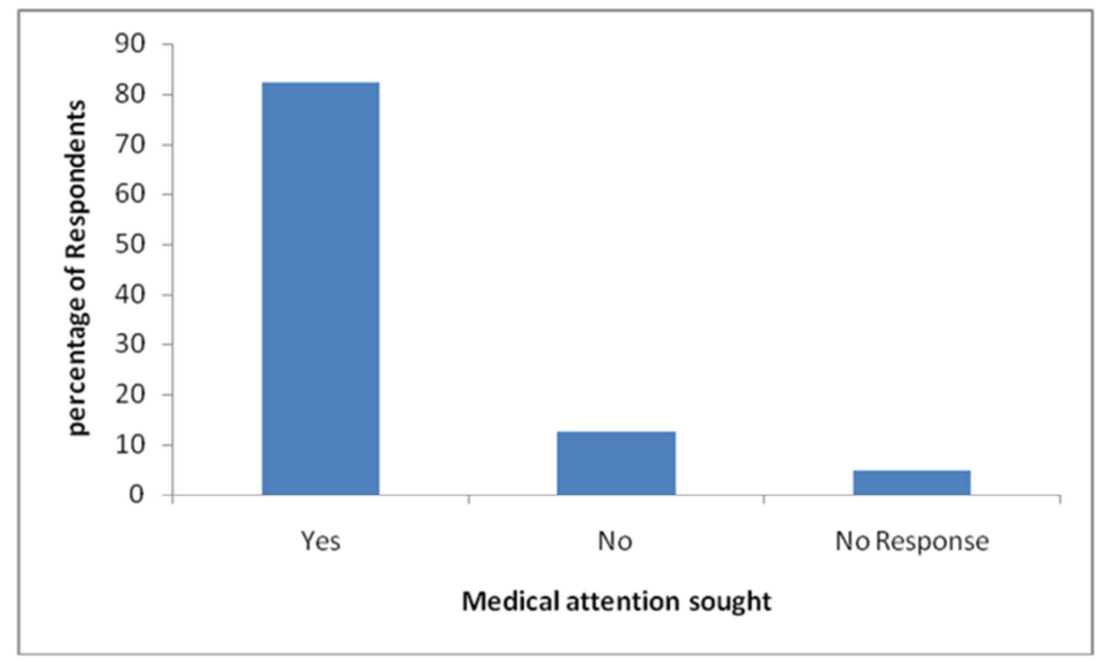

Figure 4. A Chart Showing the Attitude of Respondents towards Medical Attention.

\section{Discussion}

Research has shown that urinary incontinence occurs across all ages. Following the result of this study, urinary incontinence occurrence increases as one ages (See table 1). This is in consonant with the report of [4], which stated that the occurrence of urinary incontinence is associated with advancement in age. This is possible because increase in age is associated with loss of muscle tone and contractility. Loss of muscle tone and contractility in the pelvic floor muscles, detrusor muscles, internal and external sphincter can result in involuntary urine leakage.

The increased percentage of occurrence in married men shown in this study is because more married men $(58.1 \%)$ were found among the population of study (figure 1). There is no correlation between marital status in men and urinary incontinence.

This study has shown that alcohol, smoking, previous surgery, infections and sexually transmitted disease are the major causes of incontinence among the respondents. All these factors are known to reduce the functionality of the urinary system.

The result of this study shows that stress incontinence, functional incontinence, overflow incontinence as well as urge incontinence were the major types of incontinence found among the respondents (see figure 3). However, it has been observed that stress incontinence remains the most prevalent of all types. This is because men are prone to hard labour which could exert excessive abdominal pressure on the bladder, weakness of pelvic floor muscles and tissues and consequentially, incontinence [2]. Polydipsia, as seen in diabetes insipidus may be the leading cause of overflow incontinence in male as mentioned by [11].

Multivariate association between different risk factors of urinary incontinence in men used for this study (Table 2) has proven that infection (hematuria) remains the most predominant risk factor associated with urinary incontinence. Infection in men could damage the urethra and bladder causing both urethral and bladder dysfunction. The above factors precede urinary incontinence in men.

Figure 4 shows that a greater percentage of respondents with urinary incontinence have a positive attitude towards seeking medical care. However, only $31.6 \%$ sought for medical care in the hospital. Others sought for help from traditional medicine homes, spiritual homes, and so on. This may be as result of lack of awareness on availability of treatment in the hospital or main fear being the perception that they will be seen as dirty and unclean.

In this study, the prevalence of incontinence in men has been estimated at $37.2 \%$. Health professionals or providers may underestimate the prevalence of urinary incontinence in men because at least one-half of the affected population do not report the problem to health care personnel. Although, it is advised that Abdominal, pelvic and neurological examination should also be performed [12]. Considering the incontinent male patient, as mostly seen in urge incontinence, there is potential contribution of bladder outlet obstruction to bladder overactivity. As observed by other researchers, many men suffering from bladder overactivity will also have bladder outlet obstruction which could affect therapeutic options for patients.

\section{Conclusion}

The findings of this study have proven that urinary incontinence occurs as age increases. Stress incontinence is the most prevalent among other types of incontinence found in men. Infection is the most significant risk factor associated with incontinence in men. Urgency incontinence as part of the overactive bladder (OAB) syndrome and can often coexist with benign prostatic obstruction (BPO) in men and the initial treatment of this is conservative lifestyle changes and then medical therapy. Since incontinence in men is associated with several risk factors, it is pertinent that men should promptly report any case of incontinence to professional medical personnel. Also, this study should be carried out in rural communities for sensitization/awareness. 


\section{References}

[1] Nitti, V. W. (2001). The Prevalence of Urinary Incontinence. Rev Urol. 2001; 3 (Suppl 1): S2-S6.

[2] Urinary incontinence (2013): The management of urinary incontinence in women; NICE Clinical Guideline.

[3] Gorina Y., Schappert S., Bercovitz A., et al. (2014). Prevalence of incontinence among older Americans. Vital Health Stat 3. Vol.1

[4] Sandvik H, Hunskaar S, Seim A, et al. (1993). Validation of severity index in female urinary incontinence and its implementation in an epidemiological survey. J Epidemiol Community Health, 47: 497.

[5] Tennstedt SL, Chiu GR, Link CL, et al. (2010). The effect of severity of urine leakage on quality of life in Hispanic, White and Blackmen: the boston community health survey, Urology 75: 27.

[6] National Institute of Diabetes and Digestive and Kidney Diseases (NIDDK), 2012.

[7] Ouslander, J. G (2004). Management of Overactive Bladder. N. Engl. J med. 350 (8): 786-99.

[8] Ganong, W. F. (2008). Review of medical physiology, Macgraw-Hill. P.719.

[9] Irwin, R. S (2011). Irwin and Rippe's Intensive Care medicine. Irwin, R. S and Rippe, J. M (Eds). Philadelphia: Woller Wuwer Health/Lippincott Williams \& Wilkins. P.909.

[10] Creswell, J. W. (2013). Qualitative inquiry and research design: Choosing among five approaches ( $3^{\text {rd }}$ ed.) Thousand Oaks, CASAGE.

[11] Saito T, Ishikawa S, Ito T, et al. (1999). "Urinary Excertion of Aquaporin-2 water channel differentiates psychogenic polydipsia from central diabetes insipidus". J. Chin. Endocrinol. Metab. 84 (6): 2235-7.

[12] Urinary incontinence in neurological disease; NICE Clinical guideline (Aug 2012). 